\title{
Development of an Effective Method of Data Collection for Advertising and Marketing on the Internet
}

\author{
Hashimova Kamala \\ Institute of Information Technologies of ANAS, Baku, Azerbaijan \\ E-mail: kama25@mail.ru
}

Received: 16 March 2021; Accepted: 03 May 2021; Published: 08 August 2021

\begin{abstract}
The Internet advertising has more capabilities than other advertising tools. Taking into consideration the broad spectrum of the Internet, the study of the effectiveness indicators of the Internet advertising and the identification of problems in this field are considered to be topical issues. The article analyzes the key effectiveness indicators (KEA) to evaluate the effectiveness of the Internet advertising. Moreover, proposals for the effective use of advertising and marketing systems are also provided. Reducing the number of indicators to simplify the effective collection and analysis of the effectiveness indicators of Internet advertising can be promising. In this regard, some statistical and spectral operations are performed on the efficiency values, and effectiveness signs vector is determined. The Euclidean distance between these vectors is seen as the closeness between the two performance measures. The difference from other methods lies in the collection and distribution in the storage area, the distribution of data by the subsystem in the appropriate analysis systems. The processed information consists of numerical, temporary, logical and text data. The article uses a systematic approach and methodology for the scientific analysis of problems and ways to solve them, as well as for summing up..
\end{abstract}

Index Terms: Internet advertising, advertising effectiveness, effectiveness indicators, effective data collection.

\section{Introduction}

Recent studies show that the growth rate of the amount invested in the Internet advertising has risen. The Internet advertising is spread in quite different ways (they may include company websites, corporate logos, e-mail messages, pop-ups, banner ads, skyscraper, ads, buttons, interstitials, hyperlinks, dynamic media, and interactive games). One of the main reasons of this is that people spend a considerable amount of their time in WEB environment. For example, the Bolden Pikes and Gabi Serpentine, researchers from Niagara University, reported that, in 2012, the number of the Internet users was more than 245 million in the United States. Comparative studies show that the Internet advertising overweighs the street advertising campaigns for many components. Here, the volume of the funds invested on video ads has dramatically increased.

The main indicators of efficiency are the assessment of efficiency, determination of the economic effect of an advertising campaign, that is, a comparison of the cost of advertising and additional costs. In the practice of advertising theory, this issue has been little studied, since advertising as a powerful sales catalyst does not always have a short-term, instant purpose. Antipov and Joel-Jay Davis presented methods for determining the communicative effectiveness of advertising in Russian practice.In addition, advertising is one of the factors that seriously affect the state of sales.

Obviously, to evaluate the effectiveness of the Internet advertising, the key effectiveness indicators (KEI) should be analyzed. These system indicators show how successfully an organization operates, and along with the allied tolls, how effective the Internet advertising is. Finely-organized precise KEI is designed to provide objective assessment of the quality of the performance of an enterprise and even its professionals. Based on the results of KEI monitoring, the enterprise, its components and advertising campaigns can be adjusted.

The effectiveness of advertising is measured by its revenue. If the funds invested in the advertising campaigns bring revenue, the funds can be further expanded and the advertising campaigns may be endured. If the campaign's budget does provide revenue, it can be stopped completely.

$\mathrm{KEI}$ analysis is essential for the following parties:

- Business owners interested in the evaluation of the effectiveness of own performance;

- Department, office and business managers; 
- Everyone who wants to evaluate the effectiveness of own performance.

As noted, KEI can be used to:

- $\quad$ Analyze the effectiveness of advertising channels;

- $\quad$ Evaluate the results of the work;

- $\quad$ Correct the action strategy if necessary;

- $\quad$ Forecast the budget

When viewing the Internet through the marketing prism, the revenue of to be gained from any advertising channel through KEI can be evaluated or the channels that could be damaging can be identified.

\section{The Economic Efficiency Of Advertising}

The economic effectiveness of advertising refers to the difference between the advertising expenses and the revenue generated by the additional goods exchange affected by advertising. Depending on the success of advertising, this difference may be positive (successful advertising) or negative (unsuccessful advertising):

$$
\mathrm{E}=\left(\mathrm{AG} * \frac{C e}{100}\right)-(\mathrm{Ec}+\mathrm{Ax})
$$

Here:

AGE - Additional goods exchange affected by advertising,

Ce - Commercial Extra per unit of goods (percent by price),

Ac - Advertising cost.

Ec - Extra costs for increased goods exchanges.

In order to minimize the effectiveness of the Internet advertising, its commutative and economical effectiveness indicators should be evaluated. Key commutative indicators include:

Number of advertising display, number of unique displays, frequency of displays, intersection of audiences, number of clicks, number of unique clicks, attraction of advertisements, recognition of advertisements, number of unique users, number of visits, number of new users, geographical distribution of users, number of page views, number of operations, navigation throughout the site, CTR, frequency of clicks, frequency of visits, depth of views, duration of user's stay.

Key economic indicators include:

Cost of advertising launch, number of operations, number of customers, number of orders, number of sales, number of sales, volume of sales, CPM, CPUI, CPC, CPUC, CPUU, CPV, CPA, CPO, CPS, CPCr, frequency of orders, average purchase volume, average sales volume per customer [1].

Provides some practical advice to increase the effectiveness of advertising work. The article is dedicated to addressing some of the topical issues of data collection for advertising marketing.

\section{Problem Statement}

It should be noted that, at each stage of the advertising campaign, advertising companies and customers are involved in the analysis of certain groups of above-mentioned indicators and realize the monitoring of this group. For example, the effectiveness indicators related to the following groups can be included in the monitoring process at different stages of the interaction of the Internet advertising with the customers:

- Attention;

- Interest;

- Desire;

- Action.

These groups are also called the AIDA model which is derived from the initials [2]. These groups also describe the different stages of interaction with the client. According to the AIDA model, the customers must first pay attention to advertising, they should be interested in this advertisement, and have desire to purchase the advertised product, and finally get the product. Each of the four stages must be effective and designed with quality, otherwise the success will 
be impossible. The customer may purchase this product again if onlyhe/she is satisfied with the product. Therefore, the indicators must be properly selected for each stage. The following indicators can be selected for the above-mentioned stages:

Displaying the advertising information: number of displays, number of unique displays, intersection of audience, cost of advertising launch, frequency of displays, CPM, CPUI.

Customers attraction: attracting, remembering, recognizing.

Customer interests: number of clicks, number of unique clicks, CTR, frequency of clicks, CPC, CPUC.

Web site visits: number of unique users, number of visits, frequency of visits, number of new users, geographical distribution of users, number of page views, depth of views, site navigation and so forth.

A large number of parameters can complicate the analysis process. In order to achieve an effective solution to the problem, the number of effectiveness indicators should be reduced. In this case, the values of selected indicators should be calculated and filtered during the campaign. Moreover, the rate of the values of selected indicators should be forecasted.

\section{Problem Solution}

Obviously, certain aspects of e-advertising, including efficiency, and performance evaluation are widely discussed in scientific literature [3,6]. K. Hashimova's article published in the International Journal of Engineering and Electronic Business (IJIEEB), entitled "Analysis Methods of Internet Advertising-Marketing Information Dynamic Changes," highlights some effectiveness indicators and evaluates the dynamic variation of these indicators over time. An indicator defined in several articles and internet resources are studied from different aspects. It is noted that the daily activities the users engaged in and the technical tools they use is of great importance. Some research focus on the similarities and differences between street advertising companies and the Internet advertising [4]. The experience of individual countries in the purchase of goods and services is also studied. Some authors explore the relationship between advertising effectiveness and the advertising tools evaluating the media tools where they are uploaded.

However, as mentioned above, the large number and dynamic variation in the efficiency indicators have made it necessary to develop various clustering algorithms to evaluate these indicators and to reduce the number of parameters involved in the analysis $[5,10]$.

As noted, the number of effectiveness indicators is considerably higher. To reduce the number of these indicators and increase their effectiveness, some of these indicators have to be selected and the algorithms on these indicators have to be tested. In this regard, the number of clicks, the frequency of clicks, the number of unique users and the number of orders are taken. These indicators are denoted as CU1, CU2, CU3, CU4 for simplicity.

Selected effectiveness indicators may be included to the list of indicators to be involved in the analysis process without performing additional operations. One of such indicators is the number of unique users. Figure 1 shows an increase of this indicator from April 2016 to April 2018 (o-Rezsova). As it is seen from the line graph, the number of unique users increased rapidly within the specified timeframe. Since this indicator fairly differs from other indicators, it can be included in the list of indicators to be to be involved in the analysis process. Thus, decision is made on one of the selected effectiveness indicators to be involved in the analysis process. If there are other signs that distinguish any indicator from others, such decisions can also be made similarly. The following algorithms can be used to reduce the number of remaining effectiveness indicators[6,11].

Algorithm 1: The number of values obtained for each indicator is equalized. In this regard, assume that the number of elements of indicator CUi equals to $\mathrm{N}_{\mathrm{i}}$ and these values $N_{i}$ are collected in the intervals $\Delta_{\mathrm{it}}$ for duration

$$
\mathrm{T}_{\mathrm{i}}=\left(\mathrm{N}_{\mathrm{i}}-1\right) \Delta_{\mathrm{it}}
$$

The maximum value of the collection durations of the indicators involved in the analysis process is denoted by $\mathrm{T}$, and the maximum value of their numbers is denoted by $\mathrm{N}$ :

$$
\begin{aligned}
& \mathrm{T}=\max \left\{\mathrm{T}_{\mathrm{i}}\right\} \\
& \mathrm{N}=\max \left\{\mathrm{N}_{\mathrm{i}}\right\}
\end{aligned}
$$

Collected indicators can be expressed as the indicators $\mathrm{Ci}$ the number of which is denoted by $\mathrm{N}$. The interval between such elements will be $\mathrm{h}=\frac{\mathrm{T}}{\mathrm{N}-1}$.

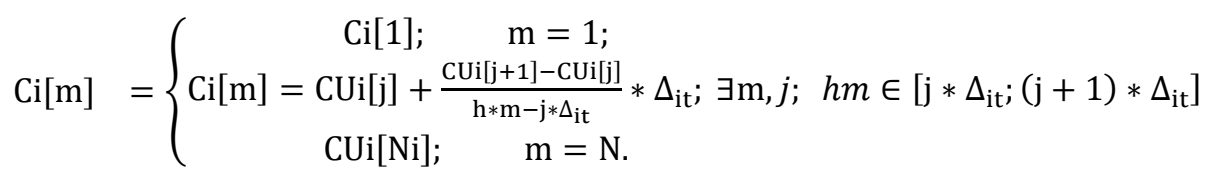


Accordingly, the elements of number will be equally distributed in the duration $\mathrm{T}$.

Note that the number and duration of the indicators can be reduced by formulas (1)-(4). In terms of conditions below

$$
\begin{aligned}
& \mathrm{T}<\min \left\{\mathrm{T}_{\mathrm{i}}\right\} \\
& \mathrm{N}<\min \left\{\mathrm{N}_{\mathrm{i}}\right\}
\end{aligned}
$$

the number of elements and distribution period of the indicators are reduced.

Algorithm 2: To perform subsequent algorithms better, the values of indicators have to be calculated to the interval $[-1 ; 1]$. Fin this regard, the maximum value of the absolute value of the elements of the indicators involved in the analysis is found, and each of the value $\mathrm{Ci}[\mathrm{m}]$ is divided by the maximum value:

$$
\begin{gathered}
\mathrm{C}_{\max }=\max \left\{\mathrm{U}_{\mathrm{i}=1}^{\mathrm{i}} \mathrm{Ci}\right\} \\
\forall \mathrm{i} \in[1, \mathrm{I}], \forall \mathrm{m} \in[1, \mathrm{~N}] \text { üçün } \mathrm{Ci}[\mathrm{m}]=\mathrm{Ci}[\mathrm{m}] / \mathrm{C}_{\max }
\end{gathered}
$$

Thus, the number of elements of the effectiveness indicators involved in the analysis is equalized and the values are calculated to the interval $[-1 ; 1]$.

The following operations on the effectiveness indicators are performed, and to define the proximity between the effectiveness indicators, the elements of the sign vector have to be determined $[8,9]$ :

Apparently, one of the key tools providing the success of e-commerce is the development of advertising of services and products offered to customers and the organization of advertising campaigns. The main advertising tools include the Internet advertising campaign. The development of advertising sites and the determined update and modification of information on these sites may increase a customer's interest in the products and services offered.

The customer or user visiting the advertising site may access the hyperlink provided here. The user's access is due to the impact of advertising. This effect, of course, may depend on the clients' age, gender, education, ethnicity, residence, etc. Regardless of the reason for the impact, there are a number of effectiveness indicators for advertising activity and many rules are available for calculating these effectiveness indicators. CTR (Click-through rate), CTB (Click-To-Buy), CTI (Click-To-Interest), VTR (View-Trough-Rate), CPV- (Cost per Visit) and CPUU (Cost per unique user), CPC (Cost per click), ROI (return on investment), CPA (Cost Per Acquisition), etc. [1].

Figure 1 shows the change in the ratio of retail sales to total sales in e-commerce between 2000 and 2020 . The graph illustrates that this proportion was steadily increasing.

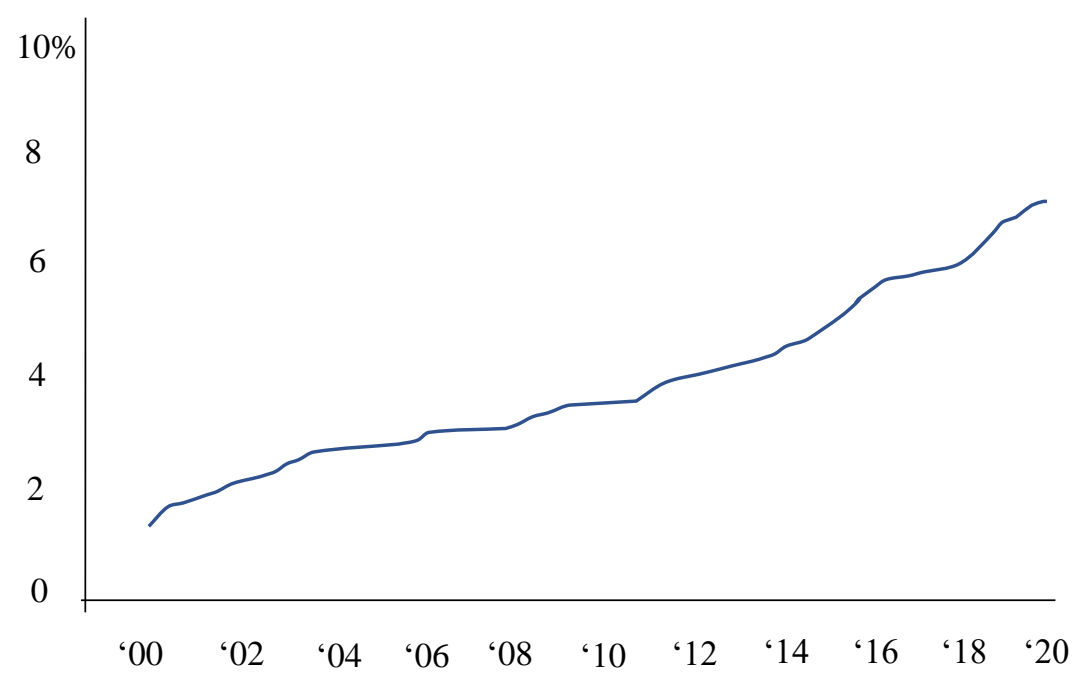

Fig. 1. Changes in the ratio of retail sales to total sales in e-commerce in 2000-2020.

Successful advertising sites and, in general, advertising campaign play a major role in achieving these increases. Various effectiveness indicators of advertising sites are analyzed to evaluate the success of the advertising campaigns. The meaning and calculation rules for some of these indicators are presented below.

An efficiency indicator called CTR (Click-through rate) is a percentage ratio of the number of users clicking the hyperlink to the number of users impressed by this hyperlink. 


$$
\mathrm{CTR}=\frac{\text { click }}{\text { impressions }} * 100
$$

The CTR is the percentage of the number of clicks per page viewed [2 - 5].

The CTR is an indicator of the potential power of the advertising site. The CTR directly affects the CPC and, ultimately, the ROI. The higher the CTR, the lower the CPC. Over the years the rapid growth of CTR is observed, while the CPC shows very little growth rate. However, this low growth rate also varies for different occupations and industries. Some studies show that the CPC is the highest and most expensive in the areas where people different genders are involved (e.g. 1.49 USD). In the e-commerce sector, this figure is $0.86 \mathrm{USD}$, and whereas in the consumer services sector it is 0.86 USD being rated third.

CTB (click to buy ratio) is the ratio of the number of people performing any type of operation on the site to the total number of people viewing the site. The actions of users can be understood as follows:

- Registering in the web site;

- Browsing specific pages or clicking the links;

- Referring to the contacts on the site;

- Calling the phone numbers provided on the site;

- Ordering goods or services from the site;

Hence, $C T B=\frac{C A}{C G}$

Here, $\mathrm{CA}$ is the number of users performing any operation on the site, and CG is the total number of visitors of the site.

Many indicators can be taken as the success indicator in e-marketing. The CPA can be taken as a financial indicator, which denotes the amount of income invested in an advertising campaign.

$$
C P A=\frac{\text { Total Compaign Cost }}{\text { Conversions }}
$$

One of the key effectiveness indicators of the advertising campaign is the ROI (Return on Investment). The ROI is a key indicator of digital marketing. To evaluate the success of an advertising campaign, the revenue of the campaign must be fully assessed. The ROI can also be called relative income. To calculate the ROI, the cost of the advertising campaign should be deduced from the income, and the obtained difference should be divided by the cost of the advertising campaign.

ROI = (Total ad Revenue - Total ad campaign cost $) /$ Total ad campaign cost

Given the importance of the ROI, knowing its value over several years is very important. In this case, it is possible to calculate the annual average over several years. To calculate the average annual ROI, the following formula can be used:

$$
R O I[i]=\left[(1+R O I)^{\frac{1}{n}}-1\right] * 100
$$

Here $\mathrm{n}$ is the number of years the ROI is calculated for.

ROI[i] is an annual value of the ROI.

With this formula, an annual ROI can be calculated even if the value of the ROI is known for a few months. For example, if the ROI is known for m months, to calculate the annual ROI, it can be written as:

$$
R O I[i]=\left[(1+R O I)^{\frac{1}{12}}-1\right] * 100
$$

Here it is taken into account that the number of $m$ months is equal to $m / 12$.

In most cases, if a firm runs a number of advertising campaigns (on the Internet, on television, in the media, on the streets and squares, stationary, etc.), it generates the comparative tables to analyze the results of these campaigns. These tables can provide preliminary information to reveal which campaigns are successful and which ones are harmful. Table 1 is a simple tool that enables such comparative analysis [7]. 
Table 1. Table of Comparative Analysis of Effectiveness Indicators.

\begin{tabular}{|c|c|c|c|c|c|}
\hline & F-1 & F-2 & F-3 & F-4 & F-5 \\
\hline Number of visits & 100000 & 400000 & 300000 & 300000 & 50000 \\
\hline Number of clicks & 1321 & 4008 & 1801 & 904 & 4066 \\
\hline CTR & $1,321 \%$ & $1,00 \%$ & $0,612 \%$ & $0,301 \%$ & $8,132 \%$ \\
\hline$\cdots$ & $\cdots$ & $\cdots$ & $\cdots$ & $\cdots$ & $\cdots$ \\
\hline Potential buyers & 372 & 1463 & 1274 & 1168 & 658 \\
\hline Number of sales & 4 & 9 & 8 & 4 & 8 \\
\hline Income & $105,672 \&$ & $324,534 \&$ & $296,976 \&$ & $280,089 \&$ & $204,432 \&$ \\
\hline Advertising costs & $14,781 \&$ & $36,847 \&$ & $32,872 \&$ & $30,633 \&$ & $9,819 \&$ \\
\hline Potential buyers cost & $39,73 \&$ & $25,19 \&$ & $25,80 \&$ & $26,23 \&$ & $14,92 \&$ \\
\hline Efficiency ratio & 7,15 & 8,81 & 9,03 & 9,14 & 20,82 \\
\hline
\end{tabular}

This table is a simple tool to show the effectiveness of advertising campaign. Each column here is related to the results of an advertising campaign. The table shows which advertising campaign of the company is more successful. The column of potential buyers in the table is calculated by various methods. For example, the number of customers who fill in a particular form can be indicated here. It can also be viewed as an interaction with customers. In some cases, this column may indicate the number of newly registered customers. Generally, the key factor here is the calculation of the ROI. In practice, the company can be considered successful if the advertising campaign generates 8 USD or more. To properly evaluate the advertising campaign, the companies that run the ad campaigns must look for different advertisements to determine whether a new user or customer appears.

A large number of effectiveness indicators may complicate the analysis process when analyzing the advertising campaigns. Therefore, the use of a small number of effectiveness indicators may simplify the analysis process. To reduce the number of effectiveness indicators, one of the two essentially identical indicators can be taken. Different value sequences of indicators obtained over a given period can be viewed as a time series. Different time series can be generated from the indicators from which the values are obtained, and the number of series with statistical proximities can be reduced. The basic solution algorithms are given in [8,12]. Some sub-programs of the developed software are provided here. Let us write the selected NN number of values of the effectiveness index involved in the analysis in the array ak. The following sub-programs can be created in the Delphi programming system.

Spectral separation sub-program:

Discrete version of the Viner-Hinge theorem:

$$
\begin{gathered}
G_{x}(f)=4 * \int_{0}^{\infty} R_{x}(\tau) \cos 2 \pi f \tau d \tau \\
R_{x}(\tau)=\int_{0}^{\infty} G_{x}(f) \cos 2 \pi f \tau d f
\end{gathered}
$$

Correlation function values:

$$
\mathrm{R}(\mathrm{nr})=\frac{1}{N N-n r} \sum_{i=0}^{N N-n r} \mathrm{ak}[\mathrm{i}] \mathrm{ak}[\mathrm{i}+\mathrm{nr}]
$$

Spectral separation:

$$
\begin{gathered}
\mathrm{G}(\mathrm{k})=2 \mathrm{~h}\left(\mathrm{R}(0)+2 \sum_{\mathrm{r}=1}^{\mathrm{m}} \mathrm{R}(\mathrm{r}) \cos \left(\frac{\pi \mathrm{rk}}{\mathrm{m}}\right)+(-1)^{\mathrm{k}} \mathrm{R}(\mathrm{m})\right. \\
\Delta t=h=\frac{1}{200} s, \quad f_{c}=\frac{1}{2 h}=100 \mathrm{Hs} \\
m=100, \quad f_{k}=\frac{f_{c}}{m} k=k
\end{gathered}
$$


for $n r:=0$ to $m$ do

begin

we: $=0$;

for $\mathrm{dn}:=0$ to $\mathrm{nn}-\mathrm{nr}$ do

we:=we+ak[dn]*ak[dn+nr];

$\mathrm{mr}[\mathrm{nr}]:=\mathrm{we}^{*}(1 /(\mathrm{nn}-\mathrm{nr}))$;

$/ / \mathrm{mr} \mathrm{ok} !$

end;

$$
\mathrm{G}(\mathrm{k})=2 \mathrm{~h}\left(\mathrm{R}(0)+2 \sum_{\mathrm{r}=1}^{\mathrm{m}} \mathrm{R}(\mathrm{r}) \cos \left(\frac{\pi \mathrm{rk}}{\mathrm{m}}\right)+(-1)^{\mathrm{k}} \mathrm{R}(\mathrm{m})\right.
$$

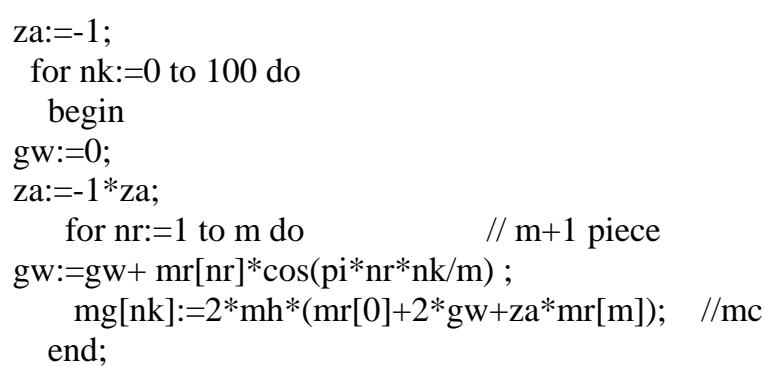

Hannan filter

$$
\begin{gathered}
\mathrm{G}(0)=0,5(\mathrm{G}(0)+\mathrm{G}(1) \\
\mathrm{G}(\mathrm{k})=0,25 \mathrm{G}(\mathrm{k}-1)+0,5 \mathrm{G}(\mathrm{k})+0,25 \mathrm{G}(\mathrm{k}+1) ; \mathrm{k}=1, \mathrm{~m}-1 \\
\mathrm{G}(\mathrm{m})=0,5(\mathrm{G}(\mathrm{m}-1)+\mathrm{G}(\mathrm{m})
\end{gathered}
$$

$\operatorname{mg}[0]:=0.5 * \operatorname{mg}[0]+0.5 * \operatorname{mg}[1]$

for $\mathrm{nk}:=1$ to $99 \mathrm{do}$

$\mathrm{mg}[\mathrm{nk}]:=0.25^{*} \mathrm{mg}[\mathrm{nk}-1]+0.5 * \mathrm{mg}[\mathrm{nk}]+0.25 * \mathrm{mg}[\mathrm{nk}+1]$;

$\mathrm{mg}[\mathrm{m}]:=0.5^{*} \mathrm{mg}[\mathrm{m}-1]+0.5^{*} \mathrm{mg}[\mathrm{m}]$;

Average value of the coordinates of the three highest values of the spectral separation: First element of the vector for $n k:=1$ to 100 do

$\operatorname{mcc}[\mathrm{nk}]:=\operatorname{mg}[\mathrm{nk}]$;

for $\mathrm{jj}:=1$ to 3 do begin

y_max:=mcc[1];

for alz := 1 to 100 do begin

if mcc[alz]>y_max then begin

y_max:=mcc[alz];

maxlar[jj]:=alz;

end;

end;

// ANALYSIS

$\operatorname{mcc}[\max l a r[j j]]:=0$;

end; // for $\mathrm{jj}:=1$ to 3 do begin

vektor[1]:=(maxlar[1]+maxlar[2]+maxlar[3])/3;

Spectral separation statistics sub-programs.

2-9 elements of the comparison vector.

If C(i)s are the magnitudes of the spectral separation components, let $S=\sum_{i=1}^{N} C(i)$. Then the following indicators (vector elements) can be calculated:

$\mu_{a m p}=\frac{1}{N} \sum_{i=1}^{N} C(i)$ Amplitude statistics:

$$
\begin{gathered}
\sigma_{a m p}=\sqrt{\frac{1}{N} \sum_{i=1}^{N}\left(C(i)-\mu_{a m p}\right)^{2}} \\
\gamma_{a m p}=\frac{1}{N} \sum_{i=1}^{N}\left(\frac{C(i)-\mu_{a m p}}{\sigma_{a m p}}\right)^{3}
\end{gathered}
$$




$$
\beta_{a m p}=\frac{1}{N} \sum_{i=1}^{N}\left(\frac{C(i)-\mu_{a m p}}{\sigma_{a m p}}\right)^{4}-3
$$

$\mu_{\text {shape }}=\frac{1}{S} \sum_{i=1}^{N} i C(i)$ Shape statistics:

$$
\begin{gathered}
\sigma_{\text {shape }}=\sqrt{\frac{1}{S} \sum_{i=1}^{N}\left(i-\mu_{\text {shape }}\right)^{2} C(i)} \\
\gamma_{\text {shape }}=\frac{1}{S} \sum_{i=1}^{N}\left(\frac{i-\mu_{\text {shape }}}{\sigma_{\text {shape }}}\right)^{3} C(i) \\
\beta_{\text {shape }}=\frac{1}{S} \sum_{i=1}^{N}\left(\frac{i-\mu_{\text {shape }}}{\sigma_{\text {shape }}}\right)^{4} C(i)-3
\end{gathered}
$$

vector[2]:=0;

for $\mathrm{jj}:=1$ to $100 \mathrm{do}$

vector[3]:=vector[2]+ mg[jj];

vector[3]:=vector[2]/100;

vector[3]:=0;

for $\mathrm{jj}:=1$ to $100 \mathrm{do}$

vector[4]:=vector[3]+sqr( mg[jj]-vector[2]);

vector[3]:=sqrt(vector[3]/100);

vector[4]:=0;

for $\mathrm{jj}:=1$ to 100 do

vector[4]:=vector[4]+sqr(( mg[jj]-vector[2])/vector[3] $) *(\operatorname{mg}[\mathrm{jj}]$-vector[2])/vector[3];

vector[4]:=vector[4]/100;

vector[5]:=0;

for $\mathrm{jj}:=1$ to 100 do

vector[5]:=vector[5]+sqr(( mg[jij]-vector[2])/vector[3])*sqr(( mg[jj]-vector[2])/vector[3]);

vector[5]:=vector[5]/100-3;

vector[6]: $=0$;

for $\mathrm{jj}:=1$ to $100 \mathrm{do}$

vector[6]:= vector[6]+ jj* $\mathrm{mg}[\mathrm{jj}]$;

vector[6]:=vector[6]/(vector[2]*100);

vector[7]:=0;

for $\mathrm{jj}:=1$ to $100 \mathrm{do}$

vector[7]:= vector[7]+ sqr(jj-vector[6])* mg[jj];

vector[7]:=vector[6]/(vector[2]*100);

vector[8]:=0;

for $\mathrm{jj}:=1$ to $100 \mathrm{do}$

vector[8]:= vector[9]+ $\operatorname{sqr}((\mathrm{jj}-\operatorname{vector}[6]) / \text { vector[7] })^{*}$

$((\mathrm{jj}$-vector[6] $) /$ vector[7] $) * \operatorname{mg}[\mathrm{jj}]$;

vector[8]:=vector[8]/(vector[2]*100);

vector[9]:=0;

for $\mathrm{jj}:=1$ to $100 \mathrm{do}$

vector[9]:= vector[9]+ sqr((jj-vector[6])/vector[7])*

$\operatorname{sqr}((\mathrm{jj}$-vector[6])/vector[7])* mg[jj];

vector[9]:=vector[9]/(vector[2]*100)-3; 
Assume that the calculated vector values are referred to the $m$-th effectiveness index. Then the vector values are written to a two-dimensional array obr[m,alz]. Euclidean distance between the two vectors of this array indicates the proximity of the vectors and, consequently, the effectiveness indicators.

\section{Sub-program for Finding Distances between Patterns}

Assume that the number of patterns, that is, the effectiveness indicators, is as obrsay. The distance from a new normal vector to each normal pattern is calculated:

for $\mathrm{jj}:=1$ to obrsay do begin

dler[jj]:=0;

for alz: $=1$ to 10 do begin

dler[jj]:=dler[jj]+sqr(obr[1,alz]-obr[jj,alz]);

end;

dler[jj]:=sqrt( dler[jj]/9);

end;

Thus, the distances between the random jj-th and 1st effectiveness indicators in the array dler[ji] can be written. If these values are adjusted from high to small, and an effectiveness indicator is maintained from each of the values $\mathrm{k}$ for the analysis, then the number of effectiveness indicators can be reduced $\mathrm{k}$ times.

\section{Conclusion}

The article analyzed the key effectiveness indicators (KEI) to evaluate the effectiveness of the Internet advertising. It was shown that the number of these indicators was quite high, and the analysis of abundant indicators caused some complications. One of the ways to address these challenges and increase the effectiveness of advertising marketing was to reduce the number of effectiveness indicators involved in the analysis. The article presented a method for the solution of this problem. The results obtained in the article can be applied to the solution of analogous issues.

Obviously, one of the ways to ensure the success of e-commerce is through the organization of the Internet advertising. Different firms are interested in delivering the goods, products and services they want to advertise to potential customers and spend a large amount of money for this. Advertisers and developers seek to improve the quality and success of their products using variety of tools. The main part of the Internet advertising is driven by Web pages, and research shows that information in this area is undergoing he dynamic changes.

Comparative studies showed that the Internet advertising was one of the most important aspects of economy.

\section{References}

[1] Ahmed, Y. and Hassan, M., 'A genetic algorithm to solve the minimum-cost paths tree problem', In International Journal of Computer Networks \& Communications (IJCNC,), Vol.7, No.4, 2015, pp 75-85.

[2] Ahmed,Y., 'A genetic algorithm for finding the K shortest paths in a network', In Egyptians informatics Journal Vol. 11, 2010, pp 75-79.

[3] Bhasin, H., and Gupta, N., 'Critical Path Problem for Scheduling using Genetic Algorithm',In Conference proceedings on Advances in Intelligent system and Computing, Springer Nature Singapore Pte Ltd., 2018, pp 15-25.

[4] Cheng,H., and Yang, S. 'Genetic Algorithms with Elitism-based Immigrants for Dynamic Shortest Path Problem in Mobile AdHoc Networks', In IEEE Congress on Evolutionary Computation, 2009, pp 3135-3145.

[5] Chowdhury,S., Das,S., and Das,A., 'Application of Genetic Algorithm in Communication Network Security', In International Journal of Innovative Research in Computer and Communication Engineering, Vol. 3, No. 1, 2015, pp 274-280.

[6] Hashimova K The role of Big Data in Internet advertising problem solution 2016 Inter J of Education and Management Engineering 4:10-20

[7] Hadiyati E Study of marketing mix and aida model to purchasing on line product in indonesia 2016 British J of Marketing Studies 4(7):49-62

[8] Bohdan P, Gabi S The Effectiveness of Online Advertising: Consumer's Perceptions of Ads on Facebook, Twitter and YouTube $2014 \mathrm{~J}$ of Applied Business and Economics 16(4):70-81

[9] Borisova O, Martynova A, Comparing the Effectiveness of Outdoor Advertising with Internet Advertising 2017 Case Study: Inetcom Company $85 \mathrm{p}$.

[10] Hashimova K Application Of Sentiment Analysis Technologies To Increase The Effectiveness Of Advertising-Marketing On Internet,

[11] Hashimova K K, Analysis Method of Internet Advertising-Marketing Information's Dynamic Changes 2017 International Journal of Information Engineering and Electronic Business vol.9, No.5, pp. 28-33

[12] Papagelis M, Plexousakis D Qualitative analysis of user-based and item-based prediction algorithms for recommendation agents 2005 Int J Eng Appl Artif Intell, 18(4) pp.781-789 
[13] Singh R., Rani A. A Survey on the Generation of Recommender Systems 2017 International Journal of Information Engineering and Electronic Business vol. 9, no.3, pp. 26-35

[14] Zhengbing Hu, Bodyanskiy Y, Tyshchenko O, Tkachov V 2017 Fuzzy Clustering Data Arrays with Omitted Observations, Inter J of Intelligent Systems and Applications 9(6):24-32

[15] Abdrakhmanova G, Vishnevsky L, Volkova G, Gohberg L Indicators of the digital economy: statistical collection 2018, M.: 268

[16] Fadil, Y. 'Routing using Genetic Algorithm for Large Networks', In Diyala Journal of Engineering Sciences, Vol. 3, 2010, pp53-70.

[17] Fall, K. and Varadhan, K. 'The ns Manual: The VINT Project between researchers at UC Berkeley, LBL, USC/ISI, and Xerox PARC', 2011, pp 1-434.

[18] Ghazal, M., Sayed, A., and Kelash, H., 'Routing Optimization using Genetic Algorithm in Ad Hoc Networks', In IEEE Int. Symposium on Signal Processing and Information Technology, 2007, pp 497-503.

[19] Gonen, B., and Yuksel, Y., 'Genetic Algorithm Finding the Shortest Path in Networks', In International Conference on Genetic and Evolutionary Methods in Deptt. Of CSE, University of Nevada, Reno,USA,2011, pp 63-73.

[20] Greg, S., Marie, J.,and Sandra, U., 'Adaptations of k-shortest path algorithms for transportation networks', In Industrial Engineering and Systems Management International Conference, 2015, pp 21-23.

[21] Heidari, A., and Delavar, M., 'A modified Genetic Algorithm for finding fuzzy shortest paths in uncertain Networks', In the International Archives of the Photogrammetry, Remote Sensing and Spatial Information Sciences, Vol. XLI-B2, XXIII ISPRS Congress, , Prague, Czech Republic, 2016, pp 12-19.

[22] Huiping, L, Cheqing J, and Bin, Y, 'Finding Top-k Shortest Paths with Diversity, In IEEE Transactions on Knowledge and Data Engineering', Vol. 30, Issue: 3, 2018, pp 3-14.

[23] Jang, P., Quan, C., and Yeh, C., 'Efficient unicast routing algorithms in Software- Defined Networking', In European Conference on Networks and Communication, 2016, pp 27-30.

[24] Jianyuan, G and Limin. J, 'A new algorithm for finding the $\mathrm{K}$ shortest paths in a time-schedule network with constraints on arcs', In Journal of Algorithms and Computational Technology,Vol.11, Issue 2, 2017, pp 70-77.

[25] Kairanbay, M.,and Hajar, M., ‘A Review and Evaluations of Shortest Path Algorithms', In International Journal of Scientific \& Technology Research, Vol. 2, Issue 6, 2013, pp 99-104.

[26] Kavitha S. and Nair T., 'A Comparative Analysis for Determining the Optimal Path using PSO and GA', In International Journal of Computer Applications (0975-8887) Vol. 32, No.4, 2011, pp 8-12.

[27] Keivan, B., and Vahid, H., 'An improved genetic algorithm with a local optimization strategy and an extra mutation level for solving traveling salesman problem', In International Journal of Computer Science, Engineering and Information Technology (IJCSEIT), Vol. 4, Issue 4, 2014, pp 47-53.

[28] Kini, S., Ramasubramanian, S., Kvalbein, A. and Hansen, A., 'Fast Recovery from Dual-Link Failures in IP Networks', In Proceedings of IEEE International Conference on Computer Communications (INFOCOM), Rio de Janeiro, Brazil, 2009, pp $1368-1376$.

[29] Kumar, N., Misra, S., Obaidat, M., 'Collaborative Learning Automata-Based Routing for Rescue Operations in Dense Urban Regions Using Vehicular Sensor Networks', In IEEE Systems Journal, DOI: 10.1109/JSYST.2014 22335451, 2014, pp 10811090.

[30] Agarwal, U., and Gupta, V., 'Network Routing Algorithm using Genetic Algorithm and Compare with Route Guidance Algorithm', In International Journal of Scientific Research Engineering and Technology, Conference proceedings IEERET, , 2014, pp 92-96.

[31] Kumar, R. and Kumar, M. 'Exploring GA for Shortest Path Optimization in Data Networks', In Global Journal of Computer Science and Technology, Vol 10, No. 11, 2010, pp 8-13.

[32] Kumari, S. and Geethanjali, N., 'A Survey on Shortest Path Routing Algorithms for Public Transport Travel”, In Global Journal of Computer Science and Technology, Vol. 9 Issue 5 ,Ver 5., 2016, pp 73-77.

[33] Misra, S., 'An Adaptive Online Routing Algorithm for MPLS Traffic Engineering', In Proceedings of the 3rd International Conference for Upcoming Engineers (ICUE2004), IEEE Toronto, Ontario, 2004,pp 959-976.

[34] Misra, S., and Oommen, B., 'Adaptive Algorithms for Network Routing and Traffic Engineering', In Proceedings of the 19th National Conference on Artificial Intelligence,SanJose,California,USA, 2004.

[35] Misra, S., and Rajesh, G., 'Bird Flight-Inspired Routing Protocol for Mobile Ad Hoc Networks', In ACM Transactions on Autonomous and Adaptive Systems, Vol. 6, No. 4, 2011, pp 843-852.

[36] Misra, S., Ghosh, T., Obaidat, M., 'Routing Bandwidth Guaranteed Paths for Traffic Engineering in WiMAX Mesh Networks', In International Journal of Communication Systems(Wiley),Vol.27, No.11, 2012, pp. 2964-2984.

[37] Misra,S., Krishna, P., Bhiwal, A., Chawla, A., Wolfinger, B., Lee, C., 'A Learning Automata-Based Fault-Tolerant Routing Algorithm for Mobile Ad Hoc Networks', In the Journal of Supercomputing (Springer), Vol. 62, No. 1, 2012, pp. 4-23.

[38] Moza, M., and Kumar, S., , 2018, 'Routing in networks using genetic algorithm', In International Journal of Communication Networks and Distributed Systems, Vol. 20, No. 3, 2018, pp. 291-311.

[39] Obeidat, A .F. and Alshalabi, M. E., 'Improving the Performance of the Networks Using Genetic Algorithm', In Proceedings of the International Conference on Advances in Computer and Information Technology, 2012, pp 33-37.

[40] Qingson, W., Ren, C., Lifeng, N., and Yinglong, X., 'Finding Top K Shortest Simple Paths with Improved Space Efficiency’, In ACM, Vol 9, Issue 5, 2017, pp 1-6.

[41] Reza, Roshani., and Mohammad, K., 'Parallel Genetic Algorithm for Shortest Path Routing Problem with Collaborative Neighbors',In Ciência eNatura, Vol. 3,Issue 2 , 2015, pp. 328-333.

[42] Sonam, J., and Sandeep, S., 'The Application of Genetic Algorithm in the Design of Routing Protocols in MANETs: A Survey', In International Journal of Computer Science and Information Technologies, Vol. 3, No. 3, 2012, pp 4318 - 4321.

[43] Theodoros, C., and Panagiotis, B., 'Exact and Approximate Algorithms for Finding k-Shortest Paths with Limited Overlap', In 20th International Conference on Extending Database Technology (EDBT), Venice, Italy, 2017, pp 414-425. 
[44] Umit, A., Ismail, R., Cevdet, G., Beyza, Y., and Ilhami, M., 'An Idea for Finding the Shortest Driving Time Using Genetic Algorithm Based Routing Approach on Mobile Devices', In International Journal of Mathematics and Computers in Simulation, Vol. 6 , Issue 1, 2012, pp 9-16.

[45] Yang,S., Cheng, H., and Wang,F., 'Genetic Algorithms With Immigrants and Memory Schemes for Dynamic Shortest Path Routing Problems in Mobile Ad Hoc Network', In IEEE transaction on System, Man, and Cybernetics-Part C: Application and Reviews, Vol 40, No. 1, 2010, pp 52-63.

[46] Yusof, R., Khairuddin, U., and Khalid, M., 'A New Mutation Operation for Faster Convergence in Genetic Algorithm Feature Selection',In International Journal of Innovative Computing, Information and Control, Vol. 18, No. 10, 2012, pp 7363-7380.

\section{Author's Profile}

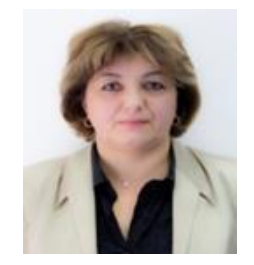

Kamala K. Hashimova, Currently she is the chief of sector at the Institute of Information Technologies of ANAS.

She closely participated in the creation of "Multimedia Gallery" base of the Institute and currently is in charge there. Participated in the creation of the www.science.az portal of ANAS.

Controls data posting in the section "Institute in mass media" of www.ict.az web-site.She teaches at the Education Center of the Institute. Author of several paper.

How to cite this paper: Hashimova Kamala," Development of an Effective Method of Data Collection for Advertising and Marketing on the Internet ", International Journal of Mathematical Sciences and Computing(IJMSC), Vol.7, No.3, pp. 1-11, 2021. DOI: $10.5815 /$ ijmsc.2021.03.01 